\title{
Macronutrient intake in advanced age: Te Puāwaitanga o Ngā Tapuwae Kia ora Tonu, Life and Living in Advanced Age: A Cohort Study in New Zealand (LiLACS NZ)
}

\author{
Carol Wham ${ }^{1}+$ Ruth Teh $^{2} \dagger$, Simon A. Moyes ${ }^{2}$, Anna Rolleston ${ }^{2}$, Marama Muru-Lanning ${ }^{3}$, Karen Hayman ${ }^{2}$, \\ Ashley Adamson ${ }^{4}$ and Ngaire Kerse ${ }^{2}$ \\ ${ }^{1}$ School of Food and Nutrition, College of Health, Massey University, North Shore, Auckland 0745, New Zealand \\ ${ }^{2}$ Department of General Practice and Primary Health Care, Faculty of Medical and Health Sciences, University of Auckland, \\ Tamaki Campus, Auckland 1142, New Zealand \\ ${ }^{3}$ James Henare Māori Research Centre, University of Auckland, Auckland 1142, New Zealand \\ ${ }^{4}$ Institute of Health and Society and Newcastle University Institute for Ageing, Newcastle University, Newcastle upon Tyne, UK \\ (Submitted 5 December 2015 - Final revision received 16 July 2016 - Accepted 19 July 2016)
}

\section{Abstract}

As part of the 12-month follow-up of the longitudinal cohort study, Life and Living in Advanced Age: A Cohort Study in New Zealand, dietary intake was assessed in 216 Māori and 362 non-Māori octogenarians using repeat 24-h multiple pass recalls. Energy and macronutrient intakes were calculated, and food items reported were allocated to food groups used in the New Zealand Adult Nutrition Survey (NZANS). Intakes were compared with the nutrient reference values (NRV) for Australia and New Zealand. The median BMI was higher for Māori (28.3 kg/m²) than for non-Māori $\left(26.2 \mathrm{~kg} / \mathrm{m}^{2}\right) P=0.007$. For Māori, median energy intake was $7.44 \mathrm{MJ} / \mathrm{d}$ for men and $6.06 \mathrm{MJ} / \mathrm{d}$ for women with $16 \cdot 3 \%$ energy derived from protein, $43.3 \%$ from carbohydrate and $38.5 \%$ from fat. Median energy intake was 7.91 and $6.26 \mathrm{MJ} / \mathrm{d}$ for non-Māori men and women, respectively, with $15.4 \%$ of energy derived from protein, $45 \%$ from carbohydrate and $36.7 \%$ from fat. For both ethnic groups, bread was the top contributor to energy and carbohydrate intakes. Protein came from beef and veal, fish and seafood, bread, milk and poultry with the order differing by ethnic groups and sex. Fat came mainly from butter and margarine. Energy-adjusted protein was higher for Māori than non-Māori $(P=0.049)$. For both ethnic groups, the median energy levels were similar, percent carbohydrate tended to be lower and percent fat higher compared with adults aged $>70$ years in NZANS. These unique cross-sectional data address an important gap in our understanding of dietary intake in this growing section of our population and highlight lack of age-appropriate NRV.

\section{Key words: Octogenarians: Dietary intake: Life and Living in Advanced Age: A Cohort Study in New Zealand: Māori}

New Zealand's population is ageing, and those aged over 80 years are the fastest growing population segment predicted to increase 6-fold by $2050^{(1)}$. Māori are the indigenous people of New Zealand. At present, $<0 \cdot 2 \%$ of Māori reach 85 years of age $^{(1)}$. However, the population of Māori aged over 80 years is expanding faster than the non-Māori octogenarian population $^{(2)}$. As older people are at increased risk of nutritional deficiencies, which closely predict morbidity and mortality ${ }^{(3)}$, social and healthcare systems will be impacted.

To date, there is very little information available about the nutritional status of those aged 80 years and over in New Zealand as the New Zealand Adult Nutrition Survey (NZANS) data are aggregated over age 55 years for Māori and over 70 years for non-Māori populations ${ }^{(4)}$. Typically, BMR declines with age because of age-related body composition changes. This physiological change along with social, psychological and medical factors predisposes older adults to weight loss ${ }^{(5)}$. Consequently, older people are at increased risk of nutritionrelated health problems such as increased functional difficulties, co-morbidities and cognitive decline ${ }^{(6)}$.

In New Zealand, the adult recommendations for dietary energy are prescribed according to age and sex with the goal of maintaining a BMI of $22 \mathrm{~kg} / \mathrm{m}^{2}$, consistent with the midpoint of the healthy weight range for all adults ${ }^{(7)}$. In older people, BMI in the overweight range are associated with optimal survi$\mathrm{val}^{(8-10)}$. Accordingly, it has been suggested that the desirable healthy weight range be set higher for improved health outcomes in older people ${ }^{(11)}$. Estimates of total energy

Abbreviations: 24-h MPR, 24-h multiple pass recall; AI, adequate intake; AMDR, acceptable macronutrient distribution range; EAR, estimated average requirement; EI, energy intake; LiLACS NZ, Life and Living in Advanced Age: A Cohort Study in New Zealand; NRV, nutrient reference values; NZANS, New Zealand Adult Nutrition Survey.

* Corresponding author: N. Kerse, fax +649373 7624, email n.kerse@auckland.ac.nz

$\dagger$ These authors contributed equally to this work. 
requirements are based on predictive equations that have not been validated in the older age group ${ }^{(7)}$.

An adequate protein intake is especially important for older adults to maintain a healthy functional status and decrease the risk of prolonged infections that lead to hospitalisation ${ }^{(12)}$. The current estimated average requirement (EAR) and RDI for protein were developed for adults aged above 70 years and may not reflect the protein needs of people aged 80 years and over, for whom little data exist on dietary intake. Thus, more detailed nutrition information is needed for those aged $80+$ years.

The applicability of these dietary intake recommendations for Māori is uncertain. Older Māori are more likely to have a higher BMI than non-Māori ${ }^{(13)}$, and this may be due to differences in body composition. In younger age groups, Māori are known to have a higher proportion of lean body mass compared with non-Māori ${ }^{(14)}$. Thus, more detailed nutrition information is needed, particularly for Māori.

Energy and macronutrient intake can be influenced by the nutrient density of the food, frequency of consumption and the quantity consumed. Knowledge of food sources in conjunction with how well older people meet current recommended nutrient intakes is important to inform future recommendations. To date, no comprehensive analysis has been undertaken to identify macronutrient and foods sources in people of advanced age. Te Puāwaitanga o Ngā Tapuwae Kia ora Tonu, Life and Living in Advanced Age: A Cohort Study in New Zealand (LiLACS NZ) is a population-based cohort study of Māori aged 80-90 years and non-Māori aged 85 years at inception in $2010^{(15,16)}$. The aim of this study was to examine energy and macronutrient intakes and the contribution of food groups to that intake in Māori and non-Māori participating in LiLACS NZ.

\section{Methods}

\section{Subjects}

LiLACS NZ recruited 937 participants from the Bay of Plenty and Rotorua regions of New Zealand in 2010 - 421 Māori born in 1920-1930 (aged 80-90 years, 56\% of those eligible) and 516 nonMāori born in 1925 (aged 85 years, 59\% of those eligible). The details of LiLACS NZ recruitment and baseline assessments have been described elsewhere ${ }^{(15,16)}$. For the Māori cohort, participant sex and age distributions were roughly equivalent to the underlying same-age population, and for the non-Māori cohort women were slightly under-represented ${ }^{(15)}$. Interviewers for Māori were fluent users of te reo Māori me ngā tikanga (Māori language and culture). Trained interviewers completed multidimensional interviews using standardised techniques, and trained research nurses completed standardised physical assessments.

A 12-month follow-up visit was completed in 2011, and a detailed dietary assessment using the 24-h multiple pass recall on two separate days $(2 \times$ MPR) was offered as part of that stage of the study. A total of 660 participants took part in any data collection at this 12-month follow-up (Fig. 1).

Of the 267 Māori engaged in the 12-month interviews, 216 (81\%) completed the dietary assessment (four participants completed the nutrition interview without completing the main questionnaire). Results of these assessments are reported in this
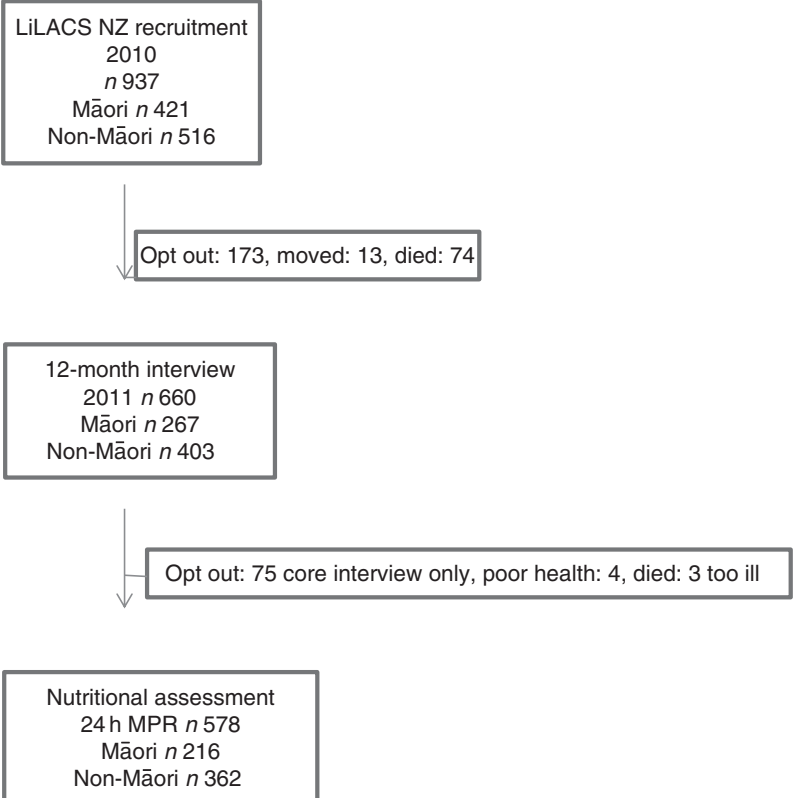

Fig.1. Flow chart of dietary assessment, 24-h multiple pass recall (24h MPR), at the 12-month follow-up interview for Life and Living in Advanced Age: A Cohort Study in New Zealand (LiLACS NZ) participants.

article. There were no differences between Māori who completed the dietary assessments and Māori who did not with regard to living arrangement, sex, age or depression status. Of the 403 non-Māori who took part in the 12-month interviews, 362 (90\%) completed the dietary assessment. There were no differences between non-Māori who completed the dietary assessment and non-Māori who did not complete the assessment with regard to living arrangement, sex, age and depression status.

This study was conducted according to the guidelines laid down in the Declaration of Helsinki, and all procedures involving human participants were approved by the Northern $\mathrm{X}$ Regional Ethical Committee (NXT 09/09/088) in 2009. Written informed consent was obtained from all the participants ${ }^{(16)}$.

\section{Measures}

Demographic information including age and sex was ascertained during baseline interviews; current living arrangement was categorised as living alone, with only the spouse or with others, which could also include the spouse. Smoking status and alcohol intake were ascertained by self-report. The New Zealand Deprivation index, an index constructed on the basis of access to resources from small area census data, based on the address at enrolment, was obtained from the Ministry of Health and was used as an indication of socio-economic deprivation ${ }^{(17)}$. Depression was assessed by the fifteen-item Geriatric Depression Scale $\left(\right.$ GDS-15) ${ }^{(18)}$, a reliable and valid self-rating depression screening scale developed specifically for older people ${ }^{(19)}$. A higher score indicates more depressive symptoms, with a cut-off of 5 or more considered to indicate significant depressive symptoms ${ }^{(20)}$.

The Short Form Health Survey (SF-12) ${ }^{(21)}$ was used to measure health-related quality of life. The maximum score is 100; any score lower than 40 is indicative of perception of poor health and above 60 indicative of perception of reasonable and better health. 
A Physical Activity Scale for the Elderly (PASE), validated in community-living, older adults ${ }^{(22)}$, was used to assess physical activity. Weight and height measurements were completed by trained research nurses following the protocol used in the NZANS $^{(23)}$. Weight was ascertained using a Tanita digital measuring scale (BC-541; Tanita Corporation) and height using a portable stadiometer (SECA 213). For participants who were unable to stand, height was estimated from the demispan, a measure closely related to height ${ }^{(24)}$, incorporating the distance from the mid sternum to the webspace between the third finger and the ring finger of the horizontally outstretched arm; two readings were obtained, and a third measurement was obtained if the difference of the first two readings was $>0.5 \mathrm{~cm}$. Height and weight were used to calculate BMI, and height, weight, age and sex were used to calculate the BMR using the Fredrix technique $^{(25)}$.

\section{Dietary assessment: 24-h multiple pass recall}

LiLACS NZ participants completed a 24-h multiple pass recall (24h MPR) on two different days of the week. The mean interval between food intake interviews was 23 (SD 36.7) $\mathrm{d}$ for Māori and 17 (SD 33.2) d for non-Māori. Interviewers were trained in the conduct of the 24-h MPR and subject to monitoring and quality controls. The protocol established for the $24 \mathrm{~h}$ MPR has been reported, and the conduct of the method has been reported elsewhere ${ }^{(26)}$

Where possible, actual food weights were recorded from food packages or food labels or were estimated using household measuring spoons or a jug. Where this was not possible, a 'Photographic Atlas of Food Portion Sizes' ${ }^{\text {(27) }}$ used in Newcastle $85+$ assessments $^{(26)}$ was adapted for use in the LiLACS NZ study. Nutrient intakes were calculated by coding all food and drinks recorded by participants using the New Zealand Food Composition Database (NZFCDB). All coding was completed by nutritionists experienced in dietary data coding. FOODfiles (2010), an electronic subset of data from the NZFCDB, was used as the main source of food composition data ${ }^{(28)}$ and contained information on fifty-eight components of 2739 foods.

\section{Food groups}

Food items reported in the $24 \mathrm{~h}$ MPR were allocated to food groups in order to calculate sources of nutrients by the type of food. The individual ingredients were assigned to separate food groups from the detailed description of the food and recipes. The thirty-three food groups used in the 2008/09 NZANS were used.

\section{Misreporting}

Misreporting of energy intake (EI) comprising both under- and over-reporting is a common problem in dietary assessments and has been described in the NZANS ${ }^{(29,30)}$. Misreporting is most commonly measured by comparing reported EI with an individual's estimated BMR $\left(\mathrm{BMR}_{\mathrm{est}}\right)$, calculated using the Fredrix equation $^{(31)}$, and by applying cut-off values as described by Goldberg, identified as the optimal method in a review ${ }^{(32)}$ based on the ratio between reported EI:BMR ${ }_{\text {est }}\left(E I: B M R_{e s t}\right)$ for a specified energy expenditure (physical activity level) ${ }^{(33)}$. In this analysis, under-reporting was defined as EI:BMR est $_{2}<0.9^{(33)}$, and EI:BMR est $>2 \cdot 0$ was used to define over-reporters ${ }^{(33,34)}$.

\section{Statistical analysis}

Differences between those completing and not completing the dietary assessment were assessed. Living arrangement and sex were tested using Cochran-Mantel-Haenszel tests; depression and age were tested using Student's $t$ test. Descriptive statistics were used to report macronutrient intake and the food groups contributing to these groups. Distribution of daily EI, carbohydrate, total sugars, sucrose, protein, fat, dietary fibre, water and alcohol intakes were examined, and mean (standard deviation) values were reported for Gaussian distribution and median (interquartile range, IQR) values for non-Gaussian distribution (Table 2). Energy-adjusted carbohydrate, protein, fat, fibre and protein per kg body weight were calculated. Comparisons used Mann-Whitney-Wilcoxon ranked sum test to check for differences between ethnic groups and sex singly. As sex varied in the ethnic groups, further multivariate generalised linear regression analyses estimated differences in intake as a continuous measure between the sexes, adjusting for age and ethnic group and between ethnic groups adjusting for age and sex. Age was necessary to adjust for as the age varied for Māori (Table 2). Table 3 shows differences in intakes according to different living arrangements, adjusted for sex in non-Māori analyses and age and sex in Māori analyses (as all non-Māori were born in the same year) using multivariate generalised linear regression models. Comparisons were also made between intake and depression, quality of life and physical activity (data not shown).

Table 4 compares nutrient reference values (NRV) achievement between sex and ethnic groups. Macronutrient levels were coded into the dichotomous, achieved NRV or outside the NRV range, and logistic regression models controlled for age (Table 4). NRV for Australia and New Zealand were used ${ }^{(7)}$ to report the proportion of participants meeting the NRV.

Sensitivity analyses were performed on macronutrient intakes excluding those with EI:BMR est $_{20} 9$ and EI:BMR ${ }_{\text {est }}>2.0$ and are presented in the online Supplementary Tables S5 and S6.

The data analyses for this study were generated using SAS/ STAT (software $12 \cdot 1$, version 9.3; SAS Institute Inc.) A $P$ value of $<0.05$ was considered statistically significant.

\section{Results}

Attrition between Wave 1 (baseline) and Wave 2 (12-month follow-up) was higher among Maori (66\% retained) than non-Māori (78\% retained) (Fig. 1). Of the 660 participants in Wave 2, 216 (81\%) Māori and 362 (90\%) non-Māori consented to food records, and 201 Māori (75\%) and 354 non-Māori (88\%) completed $2 \times 24$-h MPR with fifteen Māori (6\%) and eight nonMāori (2\%) completing only $1 \times 24-\mathrm{h}$ MPR. Comparing Wave 1 characteristics of those completing the dietary assessments with those who did not, Māori who lived with others (compared with those living alone or with spouse), those with severe depression 
and those with low physical activity were less likely to participate in the Wave 2 interview and dietary assessment $(P<0.05$ for all). In total, complete data sets for 216 Māori and 362 nonMāori participants were included in the analysis. Table 1 shows the characteristics of participants.

\section{All participants}

Overall, non-Māori consumed more alcohol, total sugars, dietary fibre and less energy-adjusted protein compared with Māori. Dietary fibre intake was generally low (Table 2).

\section{Sex}

For both Māori and non-Māori, indicative of higher median EI, men consumed higher levels of total carbohydrate, protein and fat than women (Table 2). When adjusted for energy intake, men across both groups had lower energy-adjusted carbohydrate, compared with women at both univariate and multivariate analyses. Alcohol intake was higher in men than women.

\section{Māori participants}

In all, $51 \%$ of women lived alone, and depressive symptoms were evident in $24 \%$ of Māori - $31 \%$ of men and $19 \%$ of women (Table 1). The median BMI for Māori was $28 \cdot 3 \mathrm{~kg} / \mathrm{m}^{2}$, and the median EI:BMR ${ }_{\text {est }}$ was 1.1 (IQR 0.9-1.3), similar for both sexes (1.1 (IQR $0 \cdot 8-1 \cdot 3$ ) for men and $1 \cdot 1$ (IQR 0.9-1.3 for women)). Using the cut-off of EI:BMR $\mathrm{est}<0.9$ and EI: $\mathrm{BMR}_{\mathrm{est}}>2 \cdot 0,20(36 \%)$ men and $23(27 \%)$ women were found to be potential misreporters.

Table 1. Social, physical and health characteristics of Māori and non-Māori participants by sex

(Numbers and percentages; medians and interquartile ranges (IQR))

\begin{tabular}{|c|c|c|c|c|c|c|c|c|c|c|c|c|}
\hline & \multicolumn{6}{|c|}{ Māori } & \multicolumn{6}{|c|}{ Non-Māori } \\
\hline & \multicolumn{2}{|r|}{ Men } & \multicolumn{2}{|c|}{ Women } & \multicolumn{2}{|r|}{ Total } & \multicolumn{2}{|r|}{ Men } & \multicolumn{2}{|c|}{ Women } & \multicolumn{2}{|r|}{ Total } \\
\hline & $n$ & $\%$ & $n$ & $\%$ & $n$ & $\%$ & $n$ & $\%$ & $n$ & $\%$ & $n$ & $\%$ \\
\hline \multirow{2}{*}{\multicolumn{13}{|c|}{ Age (years) }} \\
\hline & & & & & & & & & & & & \\
\hline Median & \multirow{2}{*}{\multicolumn{2}{|c|}{$\begin{array}{c}82 \\
81,85\end{array}$}} & \multirow{2}{*}{\multicolumn{2}{|c|}{$\begin{array}{c}83 \cdot 5 \\
81,86\end{array}$}} & \multirow{2}{*}{\multicolumn{2}{|c|}{$\begin{array}{c}83 \\
81,85\end{array}$}} & \multirow{2}{*}{\multicolumn{2}{|c|}{$\begin{array}{c}86 \\
85,86\end{array}$}} & \multirow{3}{*}{\multicolumn{2}{|c|}{$\begin{array}{c}86 \\
85,86\end{array}$}} & \multirow{2}{*}{\multicolumn{2}{|c|}{$\begin{array}{c}86 \\
85,86\end{array}$}} \\
\hline IQR & & & & & & & & & & & & \\
\hline \multicolumn{11}{|l|}{ Living situation } & & \\
\hline Alone & 19 & 25 & 54 & 51 & 73 & 40 & 61 & 37 & 120 & 65 & 181 & 52 \\
\hline Spouse only & 35 & 45 & 19 & 18 & 54 & 30 & 96 & 57 & 31 & 17 & 127 & 36 \\
\hline With others $\dagger$ & 23 & 30 & 33 & 31 & 56 & 30 & 10 & 6 & 33 & 18 & 43 & 12 \\
\hline \multicolumn{13}{|c|}{ Socio-economic deprivation (NZDep score) } \\
\hline 1-4 (least) & 12 & 13 & 25 & 20 & 37 & 17 & 46 & 27 & 44 & 23 & 90 & 25 \\
\hline $5-7$ & 26 & 28 & 23 & 19 & 49 & 23 & 73 & 42 & 84 & 44 & 157 & 43 \\
\hline 8-10 (most) & 54 & 59 & 76 & 61 & 130 & 60 & 53 & 31 & 62 & 33 & 115 & 32 \\
\hline \multicolumn{13}{|l|}{ Smoking status } \\
\hline Never & 29 & 32 & 63 & 53 & 92 & 43 & 62 & 36 & 130 & 68 & 192 & 53 \\
\hline Current & 10 & 11 & 16 & 13 & 26 & 12 & 11 & 6 & 6 & 3 & 17 & 5 \\
\hline Former & 53 & 58 & 41 & 34 & 94 & 44 & 99 & 58 & 54 & 28 & 153 & 42 \\
\hline \multicolumn{13}{|l|}{ Alcohol consumption } \\
\hline Never & 32 & 42 & 51 & 48 & 83 & 46 & 31 & 18 & 73 & 40 & 104 & 29 \\
\hline Monthly or less & 12 & 16 & 22 & 21 & 34 & 19 & 23 & 14 & 41 & 22 & 64 & 18 \\
\hline 2-4 times a month & 7 & 9 & 10 & 9 & 17 & 9 & 19 & 11 & 20 & 11 & 39 & 11 \\
\hline 2-3 times a week & 7 & 9 & 7 & 7 & 14 & 8 & 20 & 12 & 18 & 10 & 38 & 11 \\
\hline$\geq 4$ times a week & 18 & 24 & 16 & 15 & 34 & 19 & 76 & 45 & 32 & 17 & 108 & 31 \\
\hline \multicolumn{13}{|l|}{ Depression (GDS-15) } \\
\hline $0-4$ (mild) & 53 & 69 & 87 & 82 & 140 & 77 & 147 & 87 & 149 & 81 & 296 & 84 \\
\hline 5-9 (moderate) & 22 & 29 & 18 & 17 & 40 & 22 & 20 & 12 & 28 & 15 & 48 & 14 \\
\hline \multirow[t]{2}{*}{ 10-15 (severe) } & 2 & 3 & 1 & 1 & 3 & 2 & 2 & 1 & 6 & 3 & 8 & 2 \\
\hline & Median & IQR & Median & IQR & Median & IQR & Median & IQR & Median & IQR & Median & IQR \\
\hline \multicolumn{13}{|c|}{ Health-related quality of life } \\
\hline $\begin{array}{l}\text { SF-12 Physical } \\
\text { Health Score }\end{array}$ & 47 & 34,52 & 45 & 37,53 & 46 & 37,53 & 46 & 38,52 & 43 & 30,51 & 45 & 35,52 \\
\hline $\begin{array}{l}\text { SF-12 Mental } \\
\text { Health Score }\end{array}$ & 55 & 46,59 & 55 & 48,59 & 55 & 47,59 & 56 & 52,59 & 57 & 51,61 & 57 & 52,60 \\
\hline $\begin{array}{l}\text { Physical activity } \\
\text { (PASE) }\end{array}$ & 96 & 52,144 & 77 & 34,124 & 83 & 47,138 & 86 & 40,27 & 70 & 35,109 & 75 & 36,119 \\
\hline \multicolumn{13}{|l|}{ Anthropometry } \\
\hline Weight (kg) & 74.8 & $64 \cdot 1,85 \cdot 4$ & $65 \cdot 8$ & $57,77.9$ & $69 \cdot 7$ & $59 \cdot 8,1 \cdot 2$ & $74 \cdot 3$ & $67 \cdot 9,2 \cdot 1$ & 63.8 & $57 \cdot 3,72$ & $70 \cdot 2$ & $60 \cdot 8,78$ \\
\hline BMI $\left(\mathrm{kg} / \mathrm{m}^{2}\right)$ & 27.9 & $25 \cdot 4,31 \cdot 1$ & $28 \cdot 7$ & $24 \cdot 0,31 \cdot 6$ & $28 \cdot 3$ & $24 \cdot 7,31 \cdot 4$ & $26 \cdot 2$ & $24 \cdot 2,28 \cdot 5$ & $26 \cdot 4$ & $23 \cdot 7,30 \cdot 0$ & $26 \cdot 2$ & $24 \cdot 0,29 \cdot 2$ \\
\hline $\operatorname{BMR}(\mathrm{kJ} / \mathrm{d})$ & 6636 & 6155,7255 & 5372 & 4899,5904 & $5830 \cdot 4$ & 5109,6686 & 6573 & 6142,7004 & 5000 & 4690,5335 & 5661 & 4975,6565 \\
\hline BMR (kcal/d) & 1586 & 1471,1734 & 1284 & 1171,1411 & 1393.5 & 1221,1598 & 1571 & 1468,1674 & 1195 & 1121,1275 & 1353 & 1189,1569 \\
\hline
\end{tabular}

NZDep, New Zealand Deprivation Index; GDS, Geriatric Depression Scale, higher score, worse depressive symptoms; SF-12, Short Form Health Survey; PASE, Physical Activity Scale for the Elderly, higher score means more activity.

* Percentage of ethnic group. The proportion of women in the non-Māori group is lower than the Māori group, although this is not statistically significant $(P=0.25)$.

$\dagger$ With others includes living with extended family or in residential care (eight in residential care). 
Table 2. Daily energy and macronutrient intakes for all Mãori and non-Mãori participants by sex (Medians and interquartile ranges (IQR))

\begin{tabular}{|c|c|c|c|c|c|c|c|c|c|c|c|c|c|c|c|c|}
\hline & \multicolumn{6}{|c|}{ Māori } & \multicolumn{6}{|c|}{ Non-Māori } & \multirow[b]{3}{*}{$P($ sex $) \dagger$} & \multirow{3}{*}{$\begin{array}{l}P \text { (ethnic } \\
\text { group) } \ddagger\end{array}$} & \multirow[b]{3}{*}{$P($ sex $) \S$} & \multirow{3}{*}{$\begin{array}{l}P \text { (ethnic } \\
\text { group) } \|\end{array}$} \\
\hline & \multicolumn{2}{|c|}{ Men ( $n$ 92) } & \multicolumn{2}{|c|}{ Women (n 124) } & \multicolumn{2}{|c|}{ Total $(n 216)$} & \multicolumn{2}{|c|}{ Men ( $n$ 172) } & \multicolumn{2}{|c|}{ Women ( $n$ 190) } & \multicolumn{2}{|c|}{ Total ( $n$ 362) } & & & & \\
\hline & Median & IQR & Median & IQR & Median & IQR & Median & IQR & Median & IQR & Median & IQR & & & & \\
\hline Energy (MJ) & 7.45 & $6 \cdot 05,9 \cdot 13$ & 6.06 & $4 \cdot 80,7 \cdot 21$ & $6 \cdot 38$ & $5 \cdot 22,8 \cdot 17$ & 7.90 & $6 \cdot 70,9.57$ & $6 \cdot 27$ & $7.50,7.50$ & 7.05 & $5 \cdot 82,8 \cdot 70$ & $<0.0001$ & 0.0024 & $<0.0001$ & 0.0047 \\
\hline Energy (kcal) & 1780 & 1447,2181 & 1433 & 1147,1724 & 1526 & 1248,1953 & 1887 & 1600,2287 & 1498 & 1268,1793 & 1685 & 1390,2080 & $<0.0001$ & 0.0024 & $<.0001$ & 0.0047 \\
\hline El:BMR est $_{1}$ & $1 \cdot 1$ & $0.8-1.3$ & 1.1 & $0.9-1.3$ & $1 \cdot 1$ & $0.9-1.3$ & 1.2 & $1.0-1.5$ & 1.3 & $1 \cdot 1-1.5$ & 1.2 & $1.1-1.5$ & 0.7022 & 0.2779 & 0.9016 & 0.0030 \\
\hline Carbohydrate (g) & 183 & 157,234 & 154 & 128,190 & 167 & 137, 209 & 212 & 175,254 & 173 & 145,204 & 189 & 155,225 & $<0.0001$ & 0.0002 & 0.0154 & 0.3523 \\
\hline $\begin{array}{l}\text { Carbohydrate } \\
\text { (\% energy) }\end{array}$ & 43.0 & $37 \cdot 4,48 \cdot 2$ & 43.5 & $39 \cdot 1,49 \cdot 7$ & $43 \cdot 3$ & $38 \cdot 4,49 \cdot 2$ & $44 \cdot 3$ & $39 \cdot 4,50 \cdot 1$ & $46 \cdot 4$ & $41 \cdot 5,51 \cdot 7$ & $45 \cdot 0$ & $40 \cdot 0,50 \cdot 7$ & 0.0158 & 0.3483 & 0.0154 & 0.3524 \\
\hline Sugars, total (g) & $81 \cdot 8$ & $61 \cdot 2,115 \cdot 1$ & 71.6 & $52 \cdot 5,94 \cdot 1$ & $76 \cdot 1$ & $55 \cdot 3,99 \cdot 5$ & $99 \cdot 1$ & $78 \cdot 4,123 \cdot 0$ & $86 \cdot 2$ & $69.5,111.6$ & 92.4 & $73 \cdot 6,116 \cdot 0$ & $<0.0001$ & $<0.0001$ & $<0.0001$ & 0.0085 \\
\hline Sucrose $(\mathrm{g})$ & 38.2 & $25 \cdot 9,56 \cdot 0$ & $28 \cdot 1$ & $17 \cdot 0,40 \cdot 8$ & 31.8 & $20 \cdot 2,46 \cdot 1$ & 41.6 & $31 \cdot 5,55 \cdot 7$ & 36.4 & $24 \cdot 1,48 \cdot 6$ & 38.3 & $27 \cdot 5,52 \cdot 8$ & $<0.0001$ & 0.0114 & 0.5454 & 0.6203 \\
\hline Sugar (\% energy) & 19.9 & $14 \cdot 5,24 \cdot 4$ & 20.2 & $16 \cdot 4,25 \cdot 7$ & 20.0 & $15 \cdot 9,25 \cdot 0$ & $21 \cdot 0$ & $16 \cdot 7,24.5$ & $23 \cdot 3$ & $19 \cdot 8,27 \cdot 7$ & $22 \cdot 3$ & $18 \cdot 3,26 \cdot 3$ & $<0.0001$ & $<0.0001$ & $<0.0001$ & 0.0085 \\
\hline Protein (g) & $72 \cdot 9$ & $54.0,93.9$ & 55.4 & $46 \cdot 2,72 \cdot 3$ & 63.5 & $48 \cdot 8,81 \cdot 8$ & $75 \cdot 3$ & $61.9,87.9$ & 59.9 & $48 \cdot 0,69 \cdot 2$ & 66.5 & $52 \cdot 6,80 \cdot 6$ & $<0.0001$ & 0.2634 & 0.8694 & 0.0139 \\
\hline Protein $(\mathrm{g} / \mathrm{kg})$ & 1.05 & $0.77,1.58$ & 0.87 & $0.66,1 \cdot 19$ & 0.93 & $0.71,1.32$ & 0.98 & $0.85,1.21$ & 0.91 & $0.74,1 \cdot 13$ & 0.95 & $0.77,1.18$ & 0.0628 & 0.6504 & 0.0077 & 0.0072 \\
\hline Protein (\% energy) & $16 \cdot 3$ & $14 \cdot 2,18 \cdot 5$ & $16 \cdot 3$ & $13 \cdot 8,19 \cdot 8$ & $16 \cdot 3$ & $13 \cdot 9,19 \cdot 1$ & $15 \cdot 6$ & $13 \cdot 3,17 \cdot 7$ & $15 \cdot 3$ & $13 \cdot 4,17 \cdot 7$ & 15.4 & $13 \cdot 3,17 \cdot 7$ & 0.8838 & 0.0492 & 0.8695 & 0.0139 \\
\hline Fat $(\mathrm{g})$ & 78.4 & $53 \cdot 6,105 \cdot 0$ & $60 \cdot 0$ & $44 \cdot 6,75 \cdot 0$ & $66 \cdot 3$ & $47 \cdot 8,87 \cdot 0$ & $75 \cdot 1$ & $58 \cdot 5,100 \cdot 0$ & 60.6 & $45 \cdot 2,81 \cdot 2$ & $68 \cdot 6$ & $51.5,90 \cdot 4$ & $<0.0001$ & 0.3139 & 0.8029 & 0.0536 \\
\hline Fat (\% energy) & $38 \cdot 3$ & $32 \cdot 9,44 \cdot 4$ & $38 \cdot 7$ & $32 \cdot 4,43 \cdot 4$ & 38.5 & $32 \cdot 5,43 \cdot 7$ & $36 \cdot 2$ & $30.47,41.0$ & $37 \cdot 2$ & $31 \cdot 6,42 \cdot 4$ & 36.7 & $31 \cdot 1,42 \cdot 0$ & 0.7929 & 0.0537 & 0.8028 & 0.0536 \\
\hline SFA & $32 \cdot 3$ & $20 \cdot 2,47 \cdot 6$ & 24 & $17.4,33.8$ & 26 & $18.8,38.9$ & $32 \cdot 1$ & $23 \cdot 7,40 \cdot 7$ & 23.6 & $17 \cdot 3,33 \cdot 5$ & $28 \cdot 3$ & $19 \cdot 9,37 \cdot 4$ & $<0.0001$ & 0.6900 & 0.3898 & 0.0617 \\
\hline SFA (\% energy) & $16 \cdot 1$ & $13 \cdot 1,20 \cdot 2$ & $15 \cdot 8$ & $12 \cdot 5,19 \cdot 3$ & $15 \cdot 9$ & $12 \cdot 7,19 \cdot 4$ & $15 \cdot 1$ & $12 \cdot 6,17 \cdot 3$ & 14.4 & $11 \cdot 6,18 \cdot 2$ & 14.7 & $11 \cdot 9,17.4$ & $<0.0001$ & $<0.0001$ & 0.3899 & 0.0617 \\
\hline Dietary fibre (g) & 17.5 & $13 \cdot 5,24 \cdot 8$ & $18 \cdot 3$ & $14 \cdot 2,22 \cdot 8$ & $18 \cdot 2$ & $14 \cdot 1,23 \cdot 8$ & $22 \cdot 8$ & $18 \cdot 6,28 \cdot 6$ & 20.4 & $15 \cdot 3,25 \cdot 7$ & $21 \cdot 7$ & $17 \cdot 1,27 \cdot 4$ & 0.0009 & $<0.0001$ & $<0.0001$ & 0.1955 \\
\hline $\begin{array}{r}\text { Dietary fibre/MJ } \\
\text { energy intake }\end{array}$ & $2 \cdot 6$ & $2 \cdot 0,3 \cdot 0$ & 3.1 & $2 \cdot 6,3 \cdot 7$ & $2 \cdot 9$ & $2 \cdot 2,3 \cdot 5$ & $2 \cdot 9$ & $2.4,3.5$ & $3 \cdot 1$ & $2 \cdot 6,3 \cdot 8$ & 3.0 & $2 \cdot 5,3.6$ & $<0.0001$ & $<0.0001$ & $<0.0001$ & 0.1955 \\
\hline Water (litres) & $2 \cdot 1$ & $1 \cdot 7,2.46$ & 1.98 & $1 \cdot 6,2 \cdot 34$ & 2.05 & $1 \cdot 66,2 \cdot 39$ & $2 \cdot 23$ & $1.96,2.54$ & 2.09 & $1.73,2.44$ & $2 \cdot 16$ & $1.85,2.48$ & 0.3146 & 0.187 & $<0.0001$ & 0.8529 \\
\hline Alcohol (g) & 0 & $0,7 \cdot 80$ & 0 & 0,0 & 0 & $0,0.33$ & 0.39 & $0,18.98$ & 0 & $0,0.39$ & 0 & $0,10.80$ & 0.0005 & 0.0048 & $<0.0001$ & 0.0015 \\
\hline
\end{tabular}

El:BMR, ratio of energy intake to estimated BMR (BMR estimated using the Fredrix formula); \% energy, percent of energy intake; g/kg, grams per kilogram body weight.

* Median IQR is presented unless specified as \% energy.

† Comparing all men and all women, Wilcoxon's univariate non-parametric test.

‡ Comparing all Mãori with all non-Māori, Wilcoxon’s univariate non-parametric test.

$\S$ Comparing all men and all women, multivariate generalised linear model controlling for age and ethnicity.

I| Comparing all Mãori with all non-Māori, multivariate generalised linear model controlling for age and sex. 
Table 3. Daily energy and macronutrient intakes of Life and Living in Advanced Age: A Cohort Study in New Zealand participants by living situation

\begin{tabular}{|c|c|c|c|c|c|c|}
\hline \multirow[b]{2}{*}{ Macronutrients } & \multicolumn{3}{|c|}{ Māori } & \multicolumn{3}{|c|}{ Non-Māori } \\
\hline & Alone ( $n$ 73) & Spouse only ( $n$ 54) & With others $(n 56)$ & Alone $(n 181)$ & Spouse only ( $n 127)$ & With others ( $n$ 43) \\
\hline Energy (MJ) & $6 \cdot 3$ & $7 \cdot 1$ & $6 \cdot 4$ & $6 \cdot 7$ & $7 \cdot 7$ & $6 \cdot 6$ \\
\hline Energy (kcal) & 1503 & 1707 & 1522 & 1600 & 1843 & 1585 \\
\hline Carbohydrate (g) & 155 & 177 & 169 & 187 & 197 & $174^{*}$ \\
\hline$\%$ Energy & 43.0 & $43 \cdot 1$ & $45 \cdot 5$ & $46 \cdot 4$ & 43.3 & $47 \cdot 2^{\star \star}$ \\
\hline Fat $(\mathrm{g})$ & $64 \cdot 2$ & 71.6 & $64 \cdot 2$ & 61.5 & 77.9 & $71.4^{\star \star \star}$ \\
\hline$\%$ Energy & $37 \cdot 2$ & 38.0 & 38.9 & 34.4 & 38.0 & $37 \cdot 7^{\star \star \star}$ \\
\hline Protein $(\mathrm{g})$ & $64 \cdot 1$ & 68.6 & 58.9 & 62.5 & 74.2 & $59 \cdot 8$ \\
\hline$\%$ Energy & $16 \cdot 2$ & $16 \cdot 2$ & $16 \cdot 0$ & $15 \cdot 5$ & $15 \cdot 8$ & $15 \cdot 3$ \\
\hline
\end{tabular}

${ }^{\star} P<0.05,{ }^{\star \star} P<0.01,{ }^{\star \star \star} P<0.001$, difference across living arrangement, adjusted for age (only in Mãori as all non-Māori were aged 86 years by design) and sex comparing with non-Māori living alone and living with spouse only. No significant differences in intake detected among Māori related to living arrangement.

\section{Energy intakes and food contribution to macronutrients}

For Māori, $43 \cdot 3 \%$ of EI was from carbohydrate, $16 \cdot 3 \%$ from protein and $38.5 \%$ from fat (Table 2). There was no variation in macronutrient intake by living situation (Table 3). Controlling for age and sex, EI was not associated with depression symptoms (GDS-15), quality of life (SF-12) and physical activity level (PASE) (data not shown).

Food groups contributing to macronutrient intakes are shown in Fig. 4. Bread followed by butter and margarine, potatoes, kumara and taro (sweet potato and starchy tuber), fruit, milk and cereals were the top contributors to total energy and carbohydrate intake with the order differing by sex. Protein intake came from beef and veal (both sexes $11 \%$ ), fish and seafood (men $11 \%$, women 9\%), bread (men 10\%, women 13\%), milk (men 9\%, women $11 \%$ ) and poultry (men $9 \%$, women $11 \%$ ) with differing order of frequency by sex. Fat mainly came from butter and margarine (men 17\%, women 19\%) (Fig. 4(m) and (n)).

\section{Meeting recommendations}

Table 4 and Fig. 2 and 3 show the proportion of participants meeting the NRV. For Māori, the acceptable macronutrient distribution range (AMDR) ${ }^{(7)}$ for protein was met by $39 \%$ of women and $36 \%$ of men, for carbohydrate by $55 \%$ of women and $58 \%$ of men and for fat by most men and women. The adequate intake $(\mathrm{AI})^{(7)}$ for dietary fibre was met by $17 \%$ of women and $13 \%$ of men and for water intake by $11 \%$ of women and $4 \%$ of men.

\section{Māori participants}

In all, 65\% of non-Māori women lived alone. Depressive symptoms were evident in $16 \%$ among both men and women. The median BMI of $26 \cdot 2 \mathrm{~kg} / \mathrm{m}^{2}$ and the median EI:BMR est $_{\text {Of }} 1 \cdot 2$ (IQR 1.1-1.5) were similar for both sexes (1.2 (IQR 1.0-1.5) for men and 1.3 (IQR 1.1-1.5 for women)). Using the cut-off of EI: $\mathrm{BMR}_{\text {est }}<0.9$ and EI:BMR $\mathrm{Bst}>2 \cdot 0,27$ (19\%) men and $21(14 \%)$ women were found to be potentially misreporters (Table 1 ).

\section{Energy intakes and food contribution to macronutrients}

For non-Māori, $15.4 \%$ of EI was from protein, $45 \%$ from carbohydrate and $36.7 \%$ from fat (Table 2). Macronutrient intakes varied by living arrangement, with those living alone having lower total fat and energy-adjusted fat intake, those living with others having lower absolute amounts of carbohydrate intake, and those living with spouse only having a lower energyadjusted carbohydrate intake (Table 3). Controlling for sex, higher EI was associated with better mental health-related quality of life $(\beta 0.13$ (95\% CI $0.002,0.025), P=0.026)$ but not physical health-related quality of life, depression symptoms (GDS-15) or physical activity level (PASE) (data not shown).

Fig. 4 shows that bread was the main food group contributor to EI for both men and women (11\% respectively), followed by butter and margarine, cereals, milk, fruits, and potato, kumara and taro differing in order by sex. Bread (men 19\%, women $17 \%$ ), fruits (men $12 \%$, women $17 \%$ ), cereals (men $10 \%$, women $8 \%$ ), and potatoes, kumara and taro (men $10 \%$, women $7 \%)$ were the key contributors to carbohydrate. Protein intake for both men and women was mainly from beef and veal (men 13\%, women 10\%), bread (both sexes 12\%) and milk (men 11\%, women 12\%) with differences in the order by sex. Butter and margarine (men 18\%, women $17 \%$ ) were the main contributors of fat intake (Fig. 4(o) and (p)).

\section{Meeting recommendations}

Table 4 and Fig. 2 and 3 show that for non-Māori, $46 \%$ of women and $45 \%$ of men met the AMDR for protein, $47 \%$ of women and $56 \%$ of men for carbohydrate and the majority for fat; $28 \%$ of women and $18 \%$ of men met the AI for dietary fibre, and $11 \%$ of women and $2 \%$ of men met the AI for water intake.

Sensitivity analyses. The online Supplementary Tables S5 and S6 show results for the sample restricted to those with a EI:BMR of between 0.9 and $2 \cdot 0$. Sensitivity analyses (excluding those whose average EI suggested potential misreporting EI:BMR $<0.9$ and $>2.0$ ) for Māori made $10 \%$ difference to the intake of protein, $6 \%$ difference to the intake of carbohydrate and $4 \%$ difference to the intake of fat. For non-Māori, excluding misreporters made $1 \%$ difference to the intake of protein, $1 \%$ difference to the intake of carbohydrate and $3 \%$ difference to the intake of fat. For these sensitivity analyses, excluded Māori had significantly lower absolute intake of protein, fat and carbohydrate, but these were not significant as a percentage of EI. Non-Māori who were excluded had significantly lower intakes of fat and carbohydrate, but not protein or in the percentage of 
EI from fat, carbohydrate or protein. This indicates that, although the majority of misreporters may be under-reporting, the relative proportions of macronutrients are plausible.

Excluding misreporters, the EAR for daily protein intake was met by more women ( $88 \%$ of Māori and $84 \%$ of non-Māori women) than men ( $80 \%$ Māori and $74 \%$ non-Māori men) $(P=0.024)$. Approximately two-thirds of Māori (66\% women and $65 \%$ men) and three-quarters of non-Māori (73\% women and $72 \%$ men) met the EAR for protein intake adjusted for body weight. In addition, more women (11\%) than men (3\%) met the AI for water $(P<0 \cdot 001)$ (online Supplementary Table S6).

\section{Discussion}

This is the first study to provide a detailed examination of energy, macronutrient intake and the contribution of food groups in Māori and non-Māori octogenarians.

The median EI for Māori men and women was 7.45 and $6.06 \mathrm{MJ}$, respectively; this is lower than that estimated in the 2008/09 NZANS ${ }^{(4)}$ (8.95 and 6.59 MJ for men and women aged $51+$ years, respectively). In non-Māori, the median EI for men (7.90 MJ) was similar to the NZANS 2008/09 results (men aged $71+$ years, $7.93 \mathrm{MJ}$ ) but slightly higher in women $(6.27 \mathrm{MJ} v$. women aged 71+ years, 6.01 MJ). The 2008/09 NZANS aggregated data for older non-Māori aged 71+ years and for Māori aged 51+ years due to the small numbers above these ages included in the study. Data on the energy requirements of people over 80 years are scarce ${ }^{(36)}$. The energy requirements of eighty-seven octogenarians (mean age 82 (SD 3.1) years) participating in the Health, Aging and Body Composition study based on doubly labelled water measures of total energy expenditure were 9.24 (sD 1.57$) \mathrm{MJ} / \mathrm{d}$ for men and 7.59 (SD 1.41) MJ/d for women ${ }^{(37)}$ and comparable with the EI of participants in the current study. Independent of age, non-Māori men and women had a higher EI than Māori. Considering Māori had a similar or higher BMR and potentially higher physical activity level, this indicates that older Māori may have a negative energy balance - that is, inadequate daily EI to match energy expenditure. This finding agrees with the higher nutrition risk observed among Māori LiLACS NZ participants.

Māori dietary intake differs from non-Māori with a trend for higher fat intake contributing to total EI. This is not surprising as culturally related food patterns, living situation, BMI and BMR all differ. Kai (food) with cultural significance for Māori include fish and seafood ${ }^{(38)}$, and these were primary contributors to protein intake, especially for Māori men. Older Māori who are able to access important traditional foods on a regular basis have been found to have a better nutritional status than those without access ${ }^{(38)}$. Similarly, the nutritional quality of food intake has been shown to be improved on days when traditional foods are consumed among the indigenous peoples in Canada $^{(39)}$. Maintaining access to desired traditional foods may benefit nutritional status for older Māori.

Nutrient intake differs for older people in different living arrangements, with those living alone being at increased nutrition risk in other studies ${ }^{(40,41)}$. Māori in LiLACS NZ were more likely to live with their spouse or others such as extended family compared with non-Māori, and living alone was not 
(a)
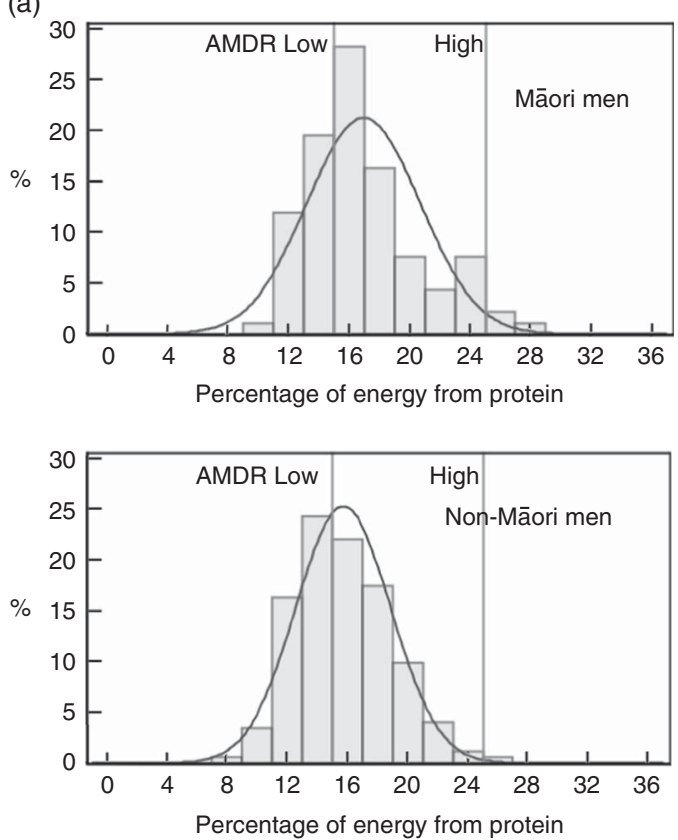

(b)
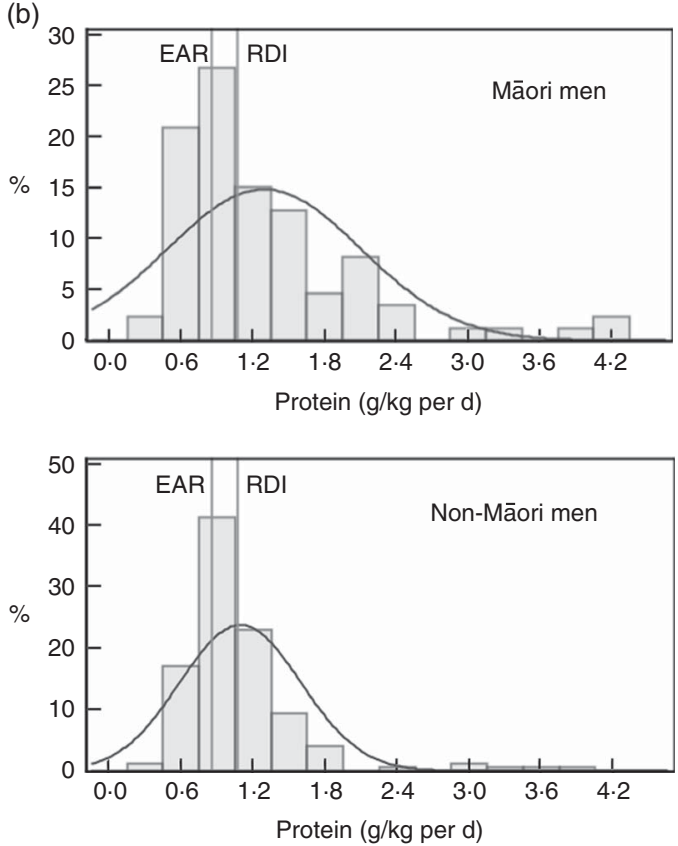
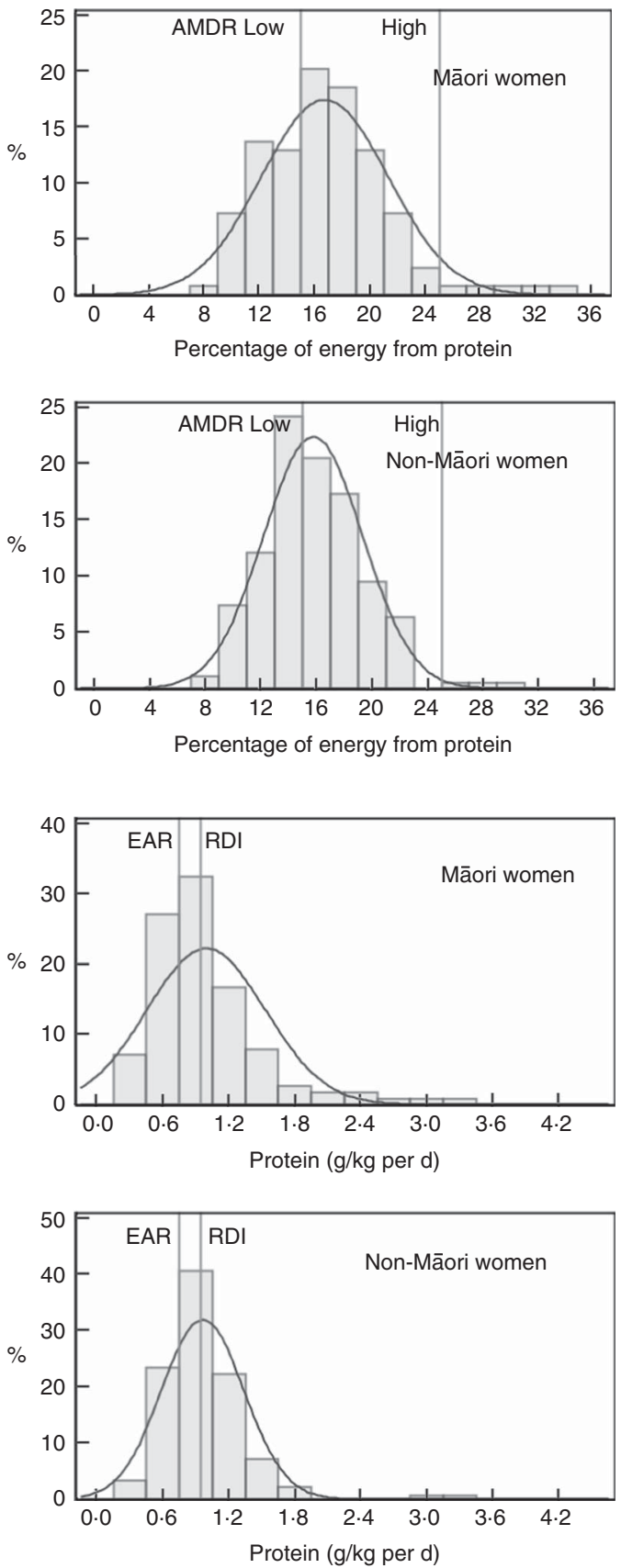

Fig. 2. Intake of protein of Life and Living in Advanced Age: A Cohort Study in New Zealand participants by sex and ethnic group: (a) percent energy from protein, (b) protein $\mathrm{g} / \mathrm{kg}$ body weight per $\mathrm{d}$. AMDR, acceptable macronutrient distribution range; EAR, estimated average requirement.

associated with a difference in macronutrient intake for Māori. Culturally driven food preparation and sharing may systematically differ between ethnic groups facilitated by $w h \bar{a}-$ naungatanga, described as relationships through shared experiences and working together, providing a sense of belonging ${ }^{(42)}$. Frequent contact with whānau (family group) may enhance food intake as well as strengthen cultural identity. For older Māori, their roles in the Māori world connected to whānau and upholding tikanga (correct cultural procedures) are positive contributors to health and well-being ${ }^{(43)}$. In LiLACS $\mathrm{NZ}$ participants, we have found that more frequent participation in cultural activities is associated with higher health-related quality of life ${ }^{(44)}$. Food intake may contribute to this association as Māori macronutrient intake differs from non-Māori and may be resilient to the potential influence of living arrangement.

For non-Māori, those who lived alone had a significantly lower fat intake, and those who lived with their spouse took less carbohydrate. Other studies have shown that those who live alone are at increased risk of malnutrition ${ }^{(45)}$, and for the non-Māori cohort our data support this.

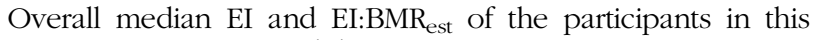
study were as expected ${ }^{(29)}$. The significance of the protein 

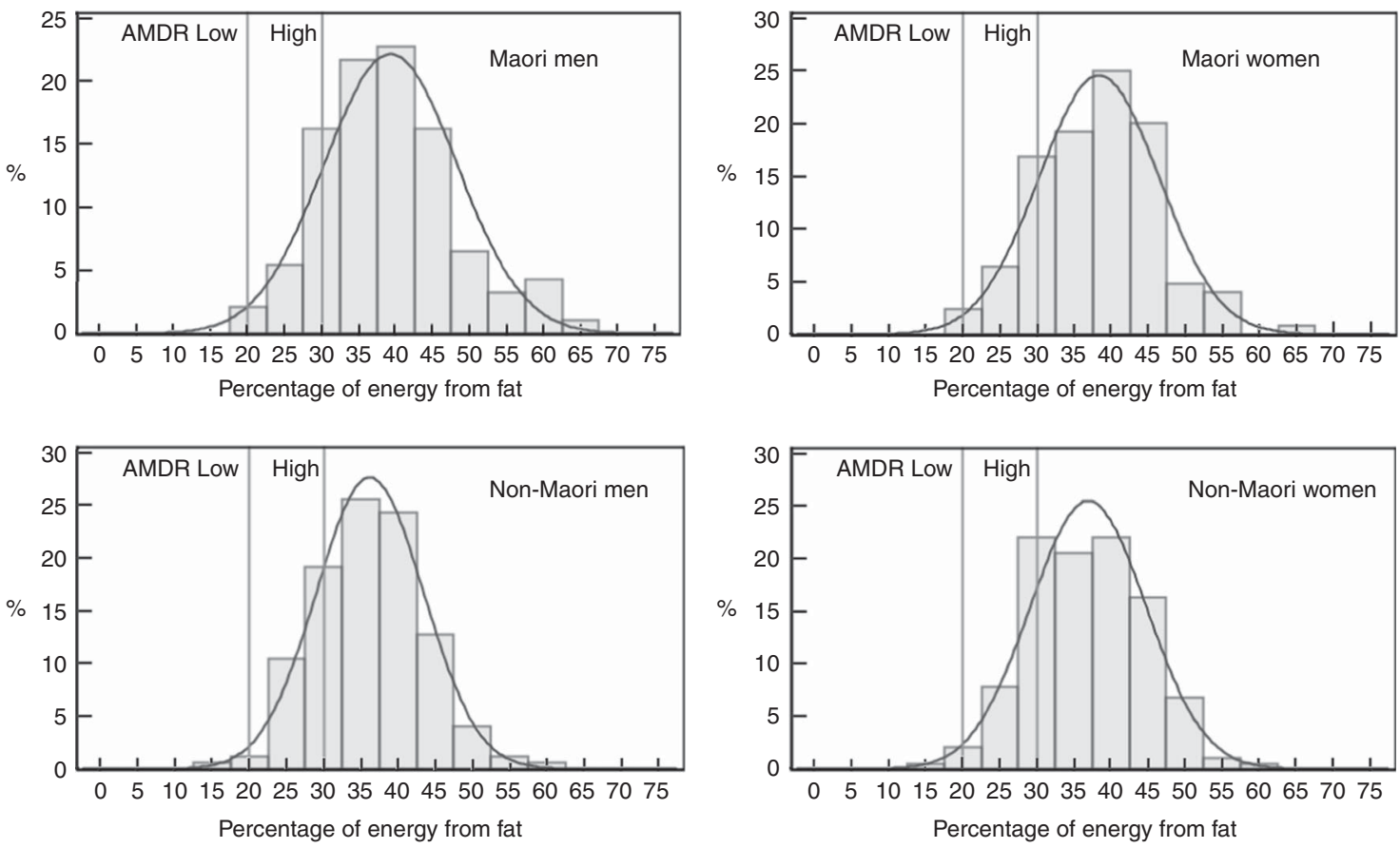

Fig. 3. Intake distribution of percentage of energy from fat for Māori and non-Māori Life and Living in Advanced Age: A Cohort Study in New Zealand participants by sex. AMDR, acceptable macronutrient distribution range.

intakes described here is unknown. In the current study, men had a higher median protein intake than women, and Māori had a marginally higher energy-adjusted protein intake than non-Māori. The median weight-adjusted protein intake for Māori and nonMāori men was 1.05 and $0.98 \mathrm{~g} / \mathrm{kg}$ per d, respectively and for Māori and non-Māori women 0.87 and $0.91 \mathrm{~g} / \mathrm{kg}$ per d, respectively. Protein intakes observed here appear to meet the current EAR for people over age 70 years but may be low, especially for women, when compared with newer recommendations $(1 \cdot 0-1 \cdot 2 \mathrm{~g} / \mathrm{kg}$ per $\mathrm{d}$ to preserve and regain lean body mass and function) made by the The PRevention in Older people-Assessment in Generalists' practices (PROT-AGe) Study Group ${ }^{(46)}$.

The sources of protein varied between sex and ethnic groups with a balanced intake of animal and vegetable protein. Bread is an important source of protein, particularly for women, as is seafood for Māori. Ensuring access to low-cost, high-protein foods that are desirable and familiar will be important to maintaining protein intake as this cohort ages. Further studies need to examine the variation in protein intake, the nature of that protein (animal or vegetable) and timing (through the day) of protein intake in relation to nutrition-related health outcomes over time.

Bread was the main contributor of energy and carbohydrate for men and women of both ethnicities in keeping with findings from the NZANS for adults over 70 years ${ }^{(4)}$. Participants consumed percent energy from carbohydrate at the lower end of the AMDR of $45-65 \%$ for people over 70 years.

Butter and/or margarine was the largest single contributor of fat for all participants $(>15 \%)$. Fat intake, as median percent energy, was above the maximum AMDR range (20-35\%), the lowest being $36 \%$ for non-Māori men, and was greater than that for adults aged 71+ years in the 2008/09 NZANS (33\%), in which butter and margarine were also the main contributors to total fat
- 16 and $15 \%$ for men and women, respectively. On the basis of the AMDR, these participants meet and exceed the minimum of $15 \%$ energy from fat proposed to ensure adequate consumption of total energy, essential fatty acids and fat-soluble vitamins ${ }^{(7,47)}$.

Dietary fibre intake among all participants was low compared with the AI for men (30 g) and women (25 g) aged 71+ years, especially for Māori men $(17.5 \mathrm{~g}$ ), and were lower than the median dietary fibre intake for those aged $71+$ years recorded in the 2008/09 NZANS. Water is considered an essential nutrient and is important in older age because of declining kidney function and use of medications such as diuretics, which predisposes older adults to the consequences of dehydration such as acute infection ${ }^{(48)}$. The median intake of water from food and fluids ranged from 2 to $2 \cdot 2$ litres lower than the AI for men $(3.4 \mathrm{l} / \mathrm{d})$ and women $(2.8 \mathrm{l} / \mathrm{d})$ over 70 years. However, the AI for water has been set at the highest level of median intake for people aged $71+$ years of each sex in the National Nutrition Survey of Australia, $1995^{(7)}$, and may not reflect the requirements of older adults living in a more temperate climate.

Dietary intakes reported here could be interpreted as less than ideal; however, this group has successfully survived into advanced age. Potentially, these food and fluid intakes may represent good nutrition for those ageing relatively successfully, and the balance of intakes will be examined longitudinally to establish prediction of maintenance of ongoing strength, high function and avoidance of adverse nutrition-related health outcomes in advanced age.

\section{Limitations}

Limitations should be considered when interpreting these results. Comparisons between Māori and non-Māori may be limited because Māori participants were younger with a higher 
(a)

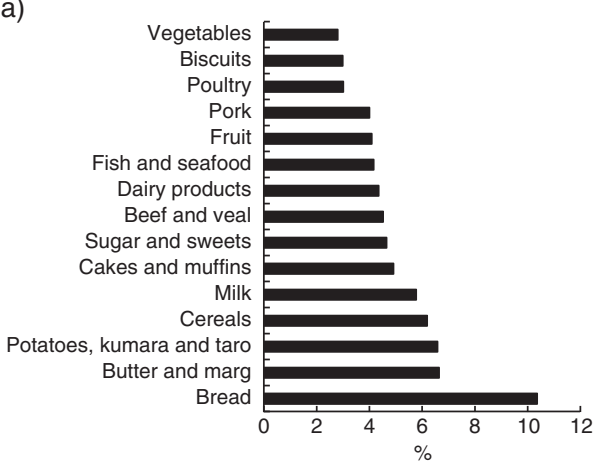

(c)

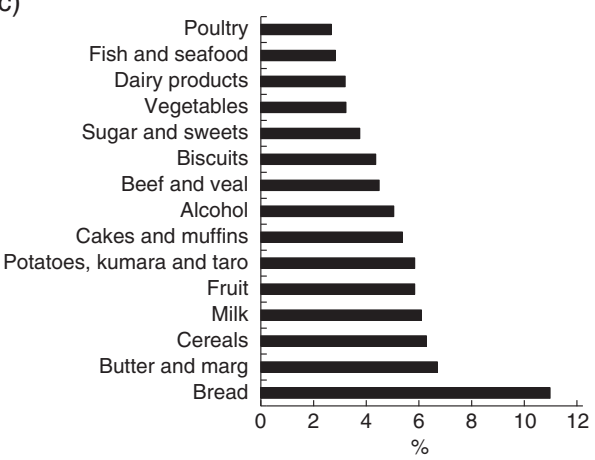

(e)

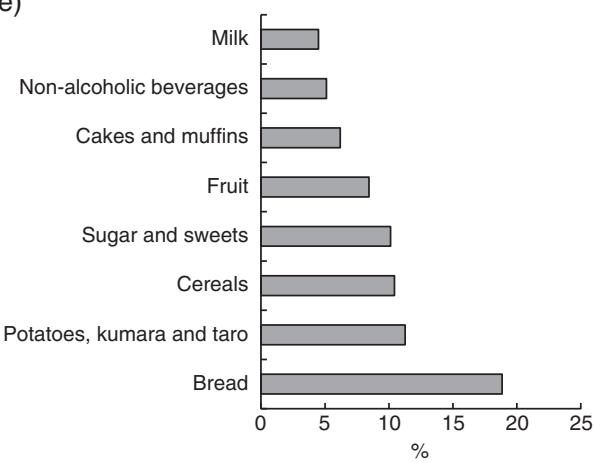

(g)

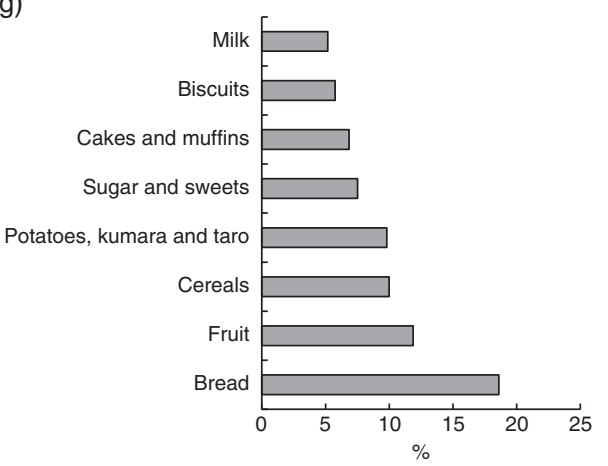

(b)

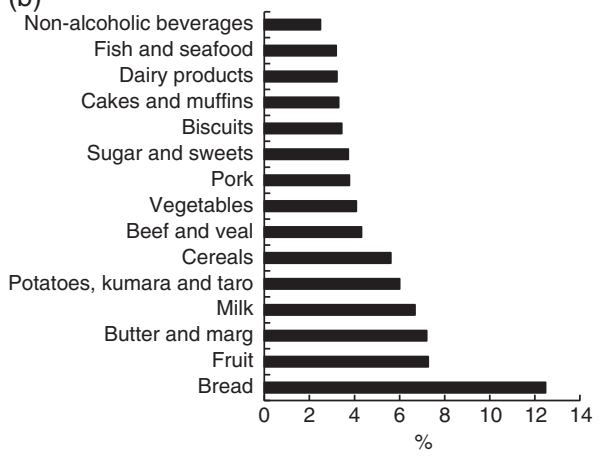

(d)

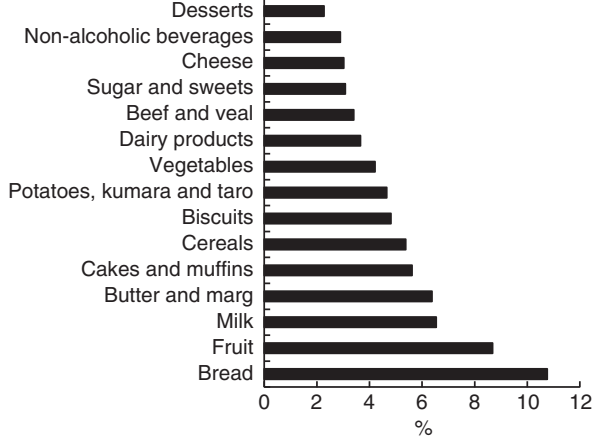

(f)

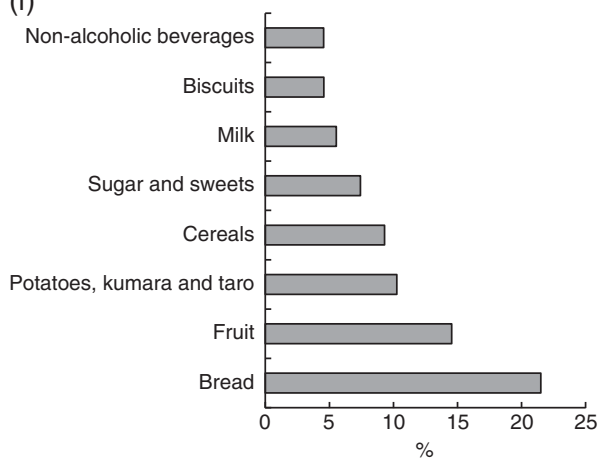

(h)

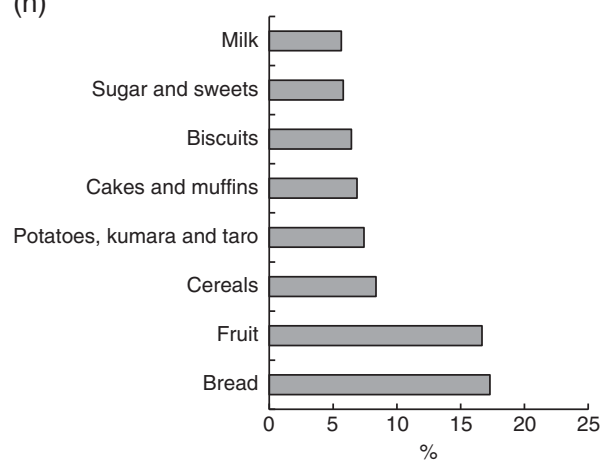

Fig. 4. (Continued on following page)

BMI than non-Māori. Culturally different food habits were evident. Generalisability of these data may be questioned because of the response rate of $<60 \%$ overall and further attrition over the 12 months follow-up. Any dietary assessment must be treated with some caution; however, inaccuracy may be less likely in this study as the 24-h MPR is potentially the best method available for this age group ${ }^{(26)}$, and the training and attention given to adherence to the protocol attempted to 
(i)

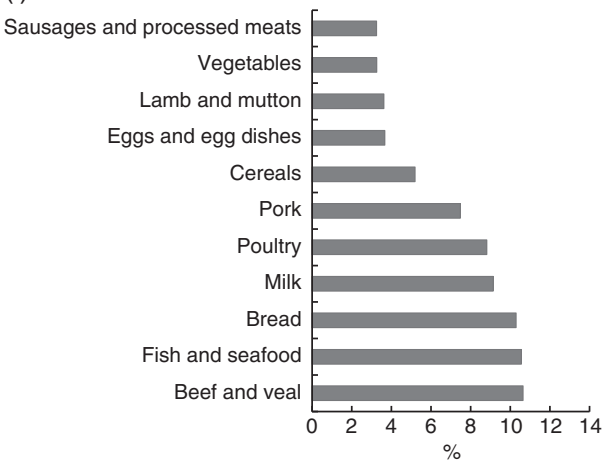

(k)

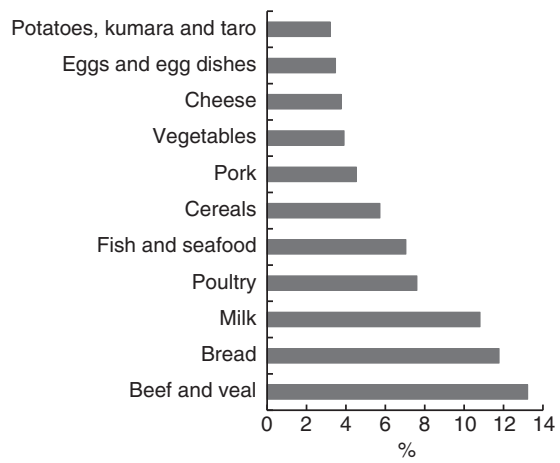

(m)

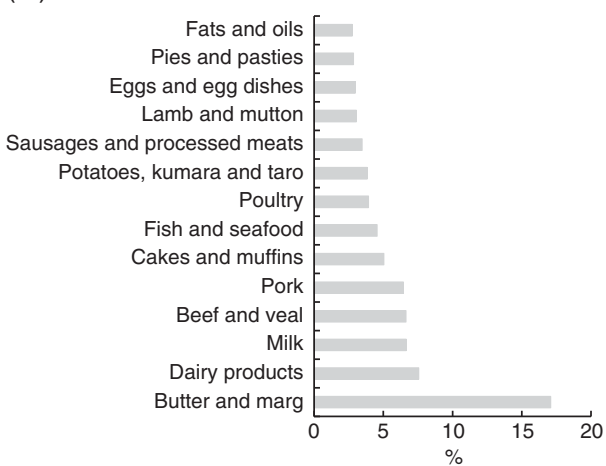

(o)

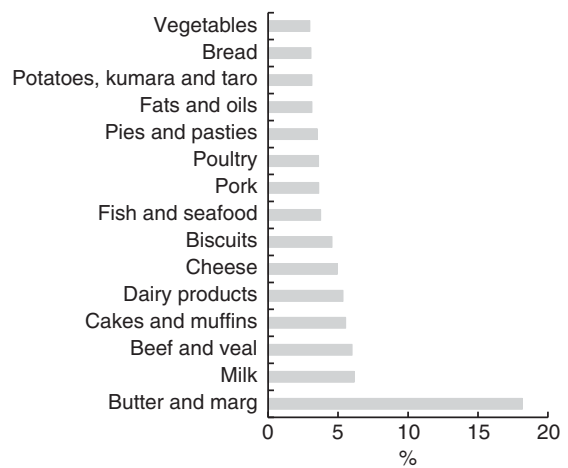

(j)

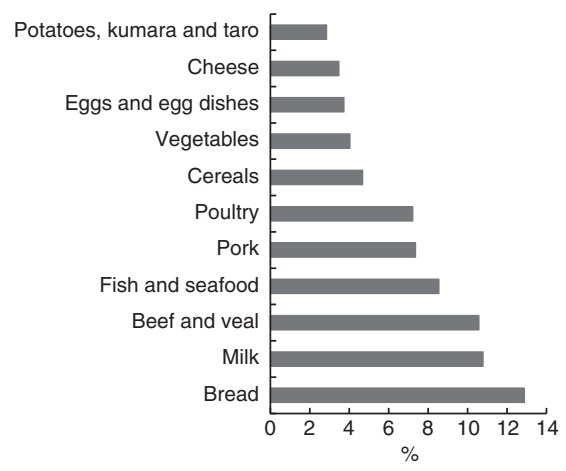

(l)

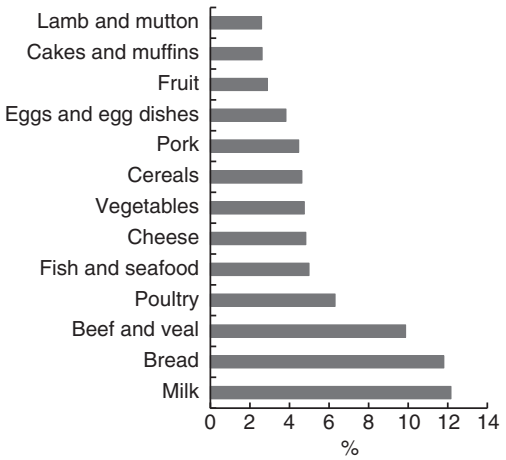

(n)

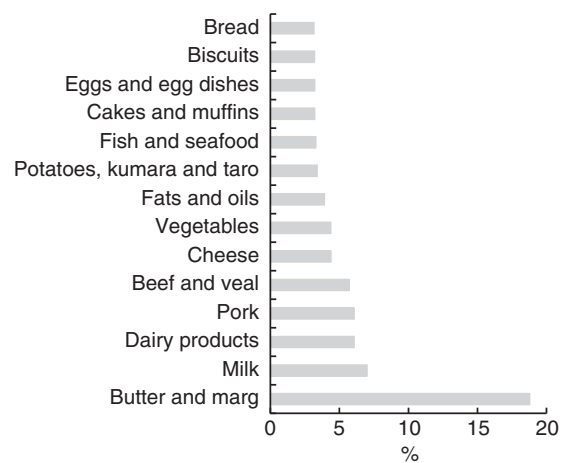

(p)

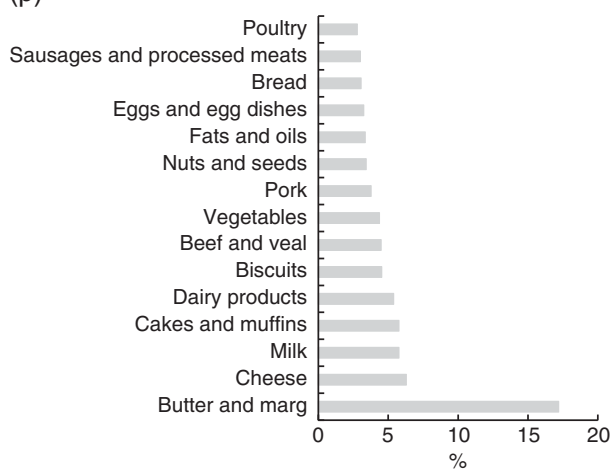

Fig. 4. (Continued from previous page). Percentage of contribution from food groups to energy and macronutrient intake for Māori and non-Māori by sex. Food sources contributing to $\geq 75 \%$ of total energy: (a) Māori men, (b) Māori women, (c) non-Māori men, (d) non-Māori women; food sources contributing to $\geq 75 \%$ of carbhohydrate: (e) Mãori men, (f) Mãori women, (g) non-Mãori men, (h) non-Mãori women; food sources contributing to $\geq 75$ \% of protein: (i) Mãori men, (j) Mãori women, (k) non-Māori men, (l) non-Mãori women; food sources contributing to $\geq 75$ \% fat: $(\mathrm{m})$ Mãori men, (n) Mãori women, (o) non-Māori men, (p) non-Mãori women. 
ensure a quality dietary assessment. An accurate assessment of nutrient status, nevertheless, requires a combination of dietary, anthropometric, biochemical and clinical measurements ${ }^{(49)}$.

We chose not to restrict our analyses to only participants with an EI:BMR between 0.9 and 2.0 as the reporting may be an accurate reflection of actual intake and some participants may be at increased nutrition risk ${ }^{(50)}$. This potentially introduces a bias that is quantified in the sensitivity analysis (online Supplementary Tables S5 and S6).

The 2008/09 NZANS used a 24-h diet recall programme to collect dietary data, and was used as the reference population to compare macronutrient and food group intakes. As the data for people aged over 70 years were aggregated, it may not reflect the food habits of the oldest old. Similarly, with limited data available, the NRV for Australia and New Zealand are based on extrapolation from younger age groups. The EAR for protein for adults aged over 70 years was increased by $25 \%$ over that of younger adults without robust data on which to base that estimate. The AI for dietary fibre was set at the median dietary fibre intake for this age group based on the 1997 National Nutrition Survey of New Zealand, plus an allowance for resistant starch not included in the food database.

Detailed comparisons between studies may be hindered by the differences in dietary assessment methods, forms of data presentation as well as participant characteristics such as geographical location, age, body composition, health and nutritional status, and level of physical activity.

\section{Conclusion}

This study provides the first detailed examination of food intake in Māori and non-Māori octogenarians. Clear sex and ethnic group differences have been reported for energy, macronutrients and dietary fibre intakes. The optimal levels of macronutrient intakes remain to be determined for the oldest old. Future guidelines may need to identify the nutritional needs of older people in relation to their functional ability and illnesses ${ }^{(51)}$. For Māori, actions that facilitate cultural-based food practices may help improve nutritionrelated outcomes. Health outcomes related to dietary intake will be examined longitudinally.

\section{Acknowledgements}

Betty McPherson advised nutrition assessment for Māori, and Hone and Florence Kameta assisted with the translation of the interview. The authors thank the organisations contracted to conduct the LiLACS NZ study in the communities of origin: Western Bay of Plenty PHO, Ngā Matāpuna Oranga Kaupapa Māori PHO, Rotorua Area Primary Health Services, Te Korowai Aroha Trust and Te Rūnunga o Ngati Pikiao, Te Rūnunga o Ngati Awa Research and Archives Trust, Te Rūnunga o Ngati Iripuaia and Te Whānau a Apanui Community Health Centre. The authors acknowledge the support of the Ministry of Health for manuscript production and the authors thank all participants and their whānau for participation.

Funders were the Health Research Council of New Zealand programme grant (HRC 06/068B, 09/068B; main funding body) and Ngā Pae o te Māramatanga (the New Zealand National
Centre for Research Excellence for Māori; funded Māori engagement and project management). A. A. is funded by the National Institute of Health Research, UK, as a Research Professor in translational research. Funders had no role in the design, analysis or writing of this article.

N. K. and A. A. conceived the study and led its design; A. R. and M. M.-L. provided Māori leadership for the study; N. K., R. T., C. W. and K. H. were involved in formulating the research question; A. A. provided specialist training for MPR; K. H. provided project management oversight; C. W., R. T. and K. H. participated in data collection; S. A. M. and R. T. performed statistical analyses; and C. W., R. T., N. K., A. A. and A. R. participated in manuscript preparation.

The authors declare that there are no conflicts of interest.

\section{Supplementary material}

For supplementary material/s referred to in this article, please visit http://dx.doi.org/doi:10.1017/S0007114516003020

\section{References}

1. Statistics New Zealand (2007) New Zealand's 65+ Population' A Statistical Volume (2007). Wellington: Statistics New Zealand

2. Ministry of Health (2011) Tatau Kura Tangata: Health of Older Mãori Chart Book. Wellington: Ministry of Health.

3. Chapman IM (2006) Nutritional disorders in the elderly. Med Clin North Am 90, 887-907.

4. University of Otago \& Ministry of Health (2011) A Focus on Nutrition: Key Findings of the 2008/09 New Zealand Adult Nutrition Survey. Wellington: Ministry of Health.

5. Morley JE (2003) Anorexia and weight loss in older persons. J Gerontol A Biol Sci Med Sci 58, M131-M137.

6. Cereda E, Pedrolli C, Zagami A, et al. (2013) Nutritional risk, functional status and mortality in newly institutionalised elderly. Br J Nutr 110, 1903-1909.

7. National Health and Medical Research Council (2006) Nutrient Reference Values for Australia and New Zealand. Canberra: NHRMC.

8. Stevens J, Cai J, Pamuk ER, et al. (1998) The effect of age on the association between body-mass index and mortality. $N$ Engl J Med 338, 1-7.

9. Grabowski DC \& Ellis JE (2001) High body mass index does not predict mortality in older people: analysis of the Longitudinal Study of Aging. J Am Geriatr Soc 49, 968-979.

10. Diehr P, O'Meara ES, Fitzpatrick A, et al. (2008) Weight, mortality, years of healthy life, and active life expectancy in older adults. J Am Geriatr Soc 56, 76-83.

11. Rejeski WJ, Marsh AP, Chmelo E, et al. (2010) Obesity, intentional weight loss and physical disability in older adults. Obes Rev 11, 671-685.

12. Volpi E, Campbell WW, Dwyer JT, et al. (2013) Is the optimal level of protein intake for older adults greater than the recommended dietary allowance? J Gerontol A Biol Sci Med Sci 68, 677-681.

13. Wham C, Teh R, Moyes S, et al. (2015) Health and social factors associated with nutrition risk: results from Life and Living in Advanced age: A Cohort Study in New Zealand (LILACS NZ). J Nutr Health Aging 19, 637-645.

14. Swinburn BA, Ley SJ \& Carmichael HE (1999) Body size and composition in Polynesians. Int J Obes Relat Metab Disord 23 , $1178-1183$ 
15. Dyall L, Kepa M, Hayman K, et al. (2013) Engagement and recruitment of Māori and non-Māori people of advanced age to LiLACS NZ. Aust N Z J Pub Health 37, 124-131.

16. Hayman K, Kerse N, Dyall L, et al. (2012) Life and Living in Advanced Age: A Cohort Study in New Zealand - Te Puawaitanga o Nga Tapuwae Kia Ora Tonu, LiLACS NZ: study protocol. BMC Geriatr 12, 33.

17. Salmond C, Crampton P \& Atkinson J (2007) NZDep2006 Index of Deprivation. Wellington: Department of Public Health, University of Otago.

18. Montorio I \& Izal M (1996) The Geriatric Depression Scale: a review of its development and utility. Int Psychogeriatr $\mathbf{8}$, 103-112.

19. Yesavage JA, Brink TL, Rose TL, et al. (1982) Development and validation of a Geriatric Depression Screening scale: a preliminary report. J Psychiatr Res 17, 37-49.

20. Yesavage J \& Sheikh J (1986) Geriatric Dression Scale (GDS) recent evidence and development of a shorter version. Clin Gerontol 5, 165-173.

21. Fleishman JA, Selim AJ \& Kazis LE (2010) Deriving SF-12v2 physical and mental health summary scores: a comparison of different scoring algorithms. Qual Life Res 19, 231-241.

22. Washburn R, McAuley E, Katula J, et al. (1999) The physical activity scale for the elderly (PASE): evidence for validity. $J$ Clin Epidemiol 52, 643-651.

23. University of Otago \& Ministry of Health (2011) Methodology Report for the 2008/09 New Zealand Adult Nutrition Survey. Wellington: Ministry of Health.

24. Hirani V \& Mindell J (2008) A comparison of measured height and demi-span equivalent height in the assessment of body mass index among people aged 65 years and over in England. Age Ageing 37, 311-317.

25. Fredrix EWHM, Soeters PB, Deerenberg IM, et al. (1990) Resting and sleeping energy expenditure in the elderly. Eur J Clin Nutr 44, 741-747.

26. Adamson AJ, Collerton J, Davies K, et al. (2009) Nutrition in advanced age: dietary assessment in the Newcastle 85+ study. Eur J Clin Nutr 63, S6-S18.

27. Nelson M, Atkinson M \& Meyers J (1997) A Photographic Atlas of Food Portion Sizes. London: Ministry of Fisheries and Food.

28. The New Zealand Institute for Plant \& Food Research Limited (2011) New Zealand FOODfiles 2010 Version 01. Palmerston North, New Zealand: The New Zealand Institute for Plant \& Food Research Limited and Wellington, New Zealand: Ministry of Health.

29. Gemming L, Jiang Y, Swinburn B, et al. (2014) Underreporting remains a key limitation of self-reported dietary intake: an analysis of the 2008/09 New Zealand Adult Nutrition Survey. Eur J Clin Nutr 68, 259-264.

30. Pikholz C, Swinburn B \& Metcalf P (2004) Under-reporting of energy intake in the 1997 National Nutrition Survey. $N Z$ Med J 117. U1079.

31. Fredrix E, Soeters P, Deerenberg I, et al. (1990) Resting and sleeping energy expenditure in the elderly. Eur J Clin Nutr $\mathbf{4 4}$, 741-747.

32. Poslusna K, Ruprich J, de Vries JH, et al. (2009) Misreporting of energy and micronutrient intake estimated by food records and 24 hour recalls, control and adjustment methods in practice. Br J Nutr 101, Suppl. 2, S73-S85.

33. Black AE (2000) Critical evaluation of energy intake using the Goldberg cut-off for energy intake:basal metabolic rate. A practical guide to its calculation, use and limitations. Int J Obes Relat Metab Disord 24, 1119.
34. Bazelmans C, Matthys C, De Henauw S, et al. (2007) Predictors of misreporting in an elderly population: the 'Quality of life after 65' study. Public Health Nutr 10, 185-191.

35. Prosky L, Asp N-G, Furda I, et al. (1985) Determination of total dietary fiber in foods and food products: collaborative study. J AOAC Int 68, 677-679.

36. Rothenberg EM, Bosaeus IG, Westerterp KR, et al. (2000) Resting energy expenditure, activity energy expenditure and total energy expenditure at age 91-96 years. Br J Nutr $\mathbf{8 4}$, 319-324.

37. Cooper JA, Manini TM, Paton CM, et al. (2013) Longitudinal change in energy expenditure and effects on energy requirements of the elderly. Nutr J 12, 73.

38. Wham C, Maxted E, Dyall L, et al. (2012) Korero te kai o te Rangatira: Nutritional wellbeing of Maori at the pinnacle of life. Nutr Diet 69, 213-216.

39. Chan L, Receveur O \& Sharp D (2012) First Nations Food, Nutrition and Environment Study (FNFNES): Results from Manitoba 2010. Prince George: University of Northern British Columbia.

40. Keller HH, Roy G \& Kane S-L (2005) Validity and reliability of SCREEN II (Seniors in the community: risk evaluation for eating and nutrition, version II). Eur J Clin Nutr 59, 1149-1157.

41. Visvanathan R, Macintosh C, Callary M, et al. (2003) The nutritional status of 250 older Australian recipients of domiciliary care services and its association with outcomes at 12 months. I Am Geriatr Soc 51, 1007-1011.

42. Locher J, Robinson C, Roth D, et al. (2005) The effect of the presence of others on caloric intake in homebound older adults. J Gerontol A Biol Sci Med Sci 60A, $1475-1478$.

43. Durie M (2004) Understanding health and illness: research at the interface between science and indigenous knowledge. Int J Epidemiol 33, 1138-1143.

44. Dyall L, Kepa M, Teh R, et al. (2014) Cultural and social factors and quality of life of Māori in advanced age: Te Puāwaitanga o Ngā Tapuwae Kia ora Tonu- Life and Living in Advanced Age: a Cohort Study in New Zealand (LiLACS NZ). $N Z$ Med J 127, 62-79.

45. Keller $\mathrm{HH}$ (2007) Promoting food intake in older adults living in the community: a review. App Physiol Nutr Metab 32, 991-1000.

46. Bauer J, Biolo G, Cederholm T, et al. (2013) Evidence-based recommendations for optimal dietary protein intake in older people: a position paper from the PROT-AGE Study Group. J Am Med Dir Assoc 14, 542-559.

47. Food and Agriculture Organization (2008) Fats and Fatty Acids in Human Nutrition. Report of an Expert Consultation. FAO Food and Nutrition Paper. Geneva: FAO.

48. Warren JL, Bacon WE, Harris T, et al. (1994) The burden and outcomes associated with dehydration among US elderly, 1991. Am J Public Health 84, 1265-1265.

49. Gibson RS (2005) Principals of Nutritional Assessement, 2nd ed. New York: Oxford University Press.

50. Wham CA, Teh R, Moyes S, et al. (2015) Health and social factors associated with nutrition risk: results from Life and Living in Advanced Age: A Cohort Study in New Zealand (LILACS NZ). J Nutr Health Aging 19, 637-645.

51. Suominen MH, Jyvakorpi SK, Pitkala KH, et al. (2014) Nutritional guidelines for older people in Finland. $J$ Nutr Health Aging 18, 861-867. 